\title{
Social Frailty Among Community-Dwelling Older Adults: Recommended Assessments and Implications
}

\author{
Hyuma Makizako ${ }^{1}$, Kota Tsutsumimoto ${ }^{2}$, Hiroyuki Shimada ${ }^{2}$, Hidenori Arai ${ }^{2}$ \\ ${ }^{1}$ Department of Physical Therapy, School of Health Sciences, Kagoshima University, Kagoshima, ${ }^{2}$ Center for Gerontology and Social \\ Science, National Center for Geriatrics and Gerontology, Obu, Japan
}

Corresponding Author: Hidenori Arai, $\mathrm{MD}, \mathrm{PhD}$ National Center for Geriatrics and Gerontology, 7-430 Morioka-cho, Obu, Aichi 474-8511, Japan

Tel \& Fax: +81-562-87-0115

E-mail: harai@ncgg.go.jp

Received: December 5, 2017 Revised: December 29, 2017 Accepted: January 5, 2018

\begin{abstract}
Even though social factors that determine frailty in older people contribute to adverse health outcomes, there is little consensus in terms of the definition of social frailty. Therefore, in this article we reviewed literature on social frailty and attempted to define the term. Although we found that living alone, social participation, economic hardship, and other such factors are associated with a decline in activities of daily living and increased risk of disability, we have not reached an agreement on either the most effective methods of assessing social frailty or the most effective interventional approaches to address social frailty. Further investigations are needed to define social frailty and identify effective interventions to promote active aging by focusing on the social aspects in older adults with social frailty. It would be reasonable to think that this approach will also improve physical and cognitive frailty.
\end{abstract}

Key Words: Health, Frailty, Aging, Activities of Daily Living

\section{INTRODUCTION}

Declining physical functioning is commonly the focus of frailty in older adults; however, the concept of frailty also includes cognitive and social aspects. ${ }^{1)}$ There is little consensus in terms of the definition of cognitive and social frailty, the criteria for frailty judgment, and indicators of frailty that should be evaluated. Social aspects of frailty include, among others, individual factors, physical and environmental factors, and economic conditions, with the quantitative evaluation of these being challenging. It has been suggested that various social factors may influence the physical and mental state of older adults, with social factors being an important aspect in understanding the state of frailty in older adults. In addition to the aforementioned, interventions aimed at promoting social activities are thought to contribute to the promotion of health and independence of the elderly.

\section{SOCIAL FACTORS ASSOCIATED WITH INCREASED RISK OF DISABILITY}

Relationships with others within residential environments and social networks, as well as social activities in the community, such as visits to the salon, have been found to be associated with future risk of dementia and risk of need for care. ${ }^{2-4)}$
In Japan, the proportion of older adults living alone has been increased. A recent report indicated that in 2010, approximately 1.39 million older men and 3.41 million older women lived alone. These figures translate to $11.1 \%$ and $20.3 \%$ of the total population of elderly men and women, respectively (2016 White Paper on Ageing Society, Cabinet Office, Government of Japan). Older adults living alone take on domestic activities, such as housework, in their daily lives. While the maintenance of independent life is expected, communication with others and connection with the society may become restricted. Such restrictions may have negative effects on these older adults, such as decrease in physical, cognitive, and social stimulations. In older men who live alone, an association between decreased social participation and increased risk of deterioration of the lively function has been noted. ${ }^{5)}$ Social frailty is a factor associated with accelerated decline in both physical and mental functioning.

In addition, as social activities frequently require higher levels of ability, it has been suggested that social roles may gradually reduce before a decline in cognitive and physical functioning is noted. For example, in a longitudinal study by Fujiwara et al. ${ }^{6}$ that sought to assess instrumental activities of daily living (IADL), intellectual mobility, and social functioning in older adults, loss of social functioning was found to occur earlier in older adults with independent IADL, intellectual mobility, and social functioning, at baseline. Further- 
more, in older adults who demonstrated independent IADL at baseline, it was found that intellectual activity and social roles, at baseline, were significant predictors of IADL decline during follow-up. Such social factors play a significant role in maintaining physical, cognitive, and mental functioning, as well as IADL in older adults. The importance of social frailty, including factors such as decreased societal connection and economic hardship, has previously been determined, and there are some agreements in terms of the definition of social frailty and the criteria associated with social frailty. Although previous studies have indicated that socioeconomic status may be associated with physical frailty levels, mental health, and mortality, ${ }^{7,8)}$ there is less evidence whether economic status increases the risk of incident disability among community-dwelling older adults. Therefore, effects of economic status on incident disability and assessment methods for economic status should be addressed in future studies. One of the challenges is to examine an indicator of frailty status in order to gain a better understanding of the social aspects that may impact older adults in Japan.

\section{ASSESSMENT OF SOCIAL FRAILTY STATUS}

Several instruments have previously been used to assess social frailty among community-dwelling older adults. See Table 1 for a list of studies that assessed social frailty and examined the association between social frailty and health outcomes among community-dwelling older adults. Part B of the Tilburg Frailty Indicator (TFI) is the most commonly used instrument to assess social frailty. ${ }^{9-13)}$ This instrument contains a number of components that assess the domains of frailty, namely, physical, psychological, and social frailty. The social domain of frailty contains three items that include "living alone," "social relations," and "social support." The domain of social frailty is used as a continuous variable, with higher scores indicating higher levels of social frailty. The TFI was developed by Gobbens et al. ${ }^{9)}$ who found that female gender was predictive of social frailty, as older women have a higher probability of living alone. In addition, they also reported that the quality of life in older adults was associated with physical and psychological domains of frailty, as well as with the social domain of frailty. ${ }^{12)}$ In the Kitakawachi Clinical Background and Outcome of Heart Failure (KICKOFF) registry (i.e., a prospective multicenter community-based cohort of heart failure patients), the super-elderly (i.e., $\geq 85$ years of age) patients with heart failure were found to be at serious risk of social frailty, as assessed by the TFI. ${ }^{13)}$ The seven-item social frailty index that assesses living arrangements, education, socioeconomic status, social network, and support provides a score between " 0 " and " 7 ." In addition, this instrument provides cutoff points indicative of level of social frailty, with higher scores indicating higher levels of social frailty. Teo et al. ${ }^{14)}$ reported that low and high levels of social frailty in older adults were associated with an increased prevalence and incidence of IADL disability, compared with older adults with nil levels of social frailty. Garre-Olmo et al. ${ }^{15)}$ employed the original operational definitions of social frailty phenotypes (i.e., living alone, lack of a person to help with activities of daily living [ADL], infrequent contact with family, friends or neighbors, absence of a confidant, and lack of support for daily living) to assess social frailty, with those older adults acquiring a score of 2 or more being categorized as socially frail older adults. The Social Vulnerability Index as an indicator of social frailty has recently been developed ${ }^{16)}$ to provide a holistic quantification of social vulnerability in older adults. This instrument has been found to be a valid measure of social frailty. ${ }^{17-19)}$

The importance of taking a comprehensive viewpoint across cognitive, mental, and social aspects of frailty, in addition to physical aspects, has been indicated. For example, it is possible to use a multifaceted approach to understand the state of frailty by employing determinants that include comprehensive aspects of frailty, as represented by the Kihon Checklist utilized in Japan. The Kihon Checklist consists of 25 items that assess exercise contents, social participation aspects, oral/nutritional status, among others. Having a score of 3 or less on this instrument classifies individuals as robust, a score of 4 to 7 as prefrail, and a score of 8 or more as frail. The risk of requiring nursing care after 3 years is approximately 2.0 times for those classified as frail and approximately 4.8 times for those classified as prefrail. ${ }^{20)}$ It has been thought that frailty can be evaluated in a comprehensive manner. However, to date, there are only few indice that focus on the social aspect of frailty. Furthermore, global consensus has not been reached in terms of providing the most effective method for evaluating the social aspect of frailty.

Based on the results of previous studies, the National Center for Geriatrics and Gerontology-Study of Geriatric Syndrome (NCGG-SGS) aimed to gain a better understanding of social frailty among community-dwelling older adults by exploring the relationship between selected determinants of social frailty and functional decline. In examining the risk of future need for support and need for care, by using measures that assess social aspects of frailty (e.g., solitary life and relationship with others), 5 aspects of social frailty were found to be associated with new incidence of need for support and long-term care within 24 months. ${ }^{4)}$ The 5 items were as follows: (1) being alone ("yes"), (2) going out less frequently compared to last year ("yes"), (3) visiting the homes of friends ("no"), (4) feeling useful to your family and friends ("no"), and (5) conversing with someone every day ("no"). ${ }^{4)}$ To assess and determine social frailty status, we prepared a questionnaire including seven questions regarding daily social activity, 
social role, and social relationships. Five (living alone, going out less frequently compared to last year, visiting friends sometimes, feeling helpful to friends or family, and talking with someone every day) of the 7 items in the self-reported questionnaire were significantly associated with incident disability, but not the other two (getting bored often and having friends to talk to on the telephone). ${ }^{4)}$ Thus, we defined social frailty using these 5 questions that showed significant associa- tions with incident disability in the NCGG-SGS.

When using these 5 items to calculate the prevalence of social frailty by defining 2 or more items corresponding to socially frail and socially prefrail as being applicable to 1 item, the prevalence of social frailty for community-dwelling seniors aged 65 years and older was $11.1 \%$, and the proportion classified as socially prefrail was $24.8 \%{ }^{211}$ In addition, the proportion of those who were classified as socially frail incre-

Table 1. List of assessment items for social frailty status

\begin{tabular}{|c|c|c|c|c|}
\hline Study & Subject & Assessment domains & Criteria & Outcome \\
\hline $\begin{array}{l}\text { Gobbens et al., } \\
2010^{9)}\end{array}$ & $\begin{array}{l}484 \text { Community-dwelling } \\
\text { persons (aged } \geq 75 \text { years) }\end{array}$ & \multirow{4}{*}{$\begin{array}{l}\text { Social frailty consists of three components } \\
\text { in the Tilburg Frailty Indicator } \\
\text { (1) living alone } \\
\text { (2) lack of social relations } \\
\text { (3) lack of social support }\end{array}$} & \multirow{4}{*}{$\begin{array}{l}\text { Continuous } \\
\text { variable with } \\
\text { higher scores } \\
\text { indicating } \\
\text { higher levels } \\
\text { of social frailty }\end{array}$} & Associated factors \\
\hline $\begin{array}{l}\text { Gobbens et al., } \\
2014^{11)}\end{array}$ & $\begin{array}{l}1,154 \text { Community-dwelling } \\
\text { older adults } \\
\text { (aged } \geq 75 \text { years) }\end{array}$ & & & QoL \\
\hline $\begin{array}{l}\text { Gobbens et al., } \\
2017^{12)}\end{array}$ & $\begin{array}{l}671 \text { Older adults } \\
\text { (aged } \geq 70 \text { years) }\end{array}$ & & & QoL \\
\hline $\begin{array}{l}\text { Takabayashi et al., } \\
2017^{13)}\end{array}$ & $\begin{array}{l}647 \text { Older adults with } \\
\text { heart failure }\end{array}$ & & & $\begin{array}{l}\text { Risk of social } \\
\text { frailty }\end{array}$ \\
\hline $\begin{array}{l}\text { Makizako et al., } \\
2015^{4)}\end{array}$ & $\begin{array}{l}4,304 \text { Older adults living in } \\
\text { the community } \\
\text { (aged } \geq 65 \text { years) }\end{array}$ & $\begin{array}{l}\text { Self-reported questionnaire including } 5 \\
\text { domains } \\
\text { (1) going out less frequently } \\
\text { (2) rarely visiting friends }\end{array}$ & \multirow[t]{2}{*}{$\begin{array}{l}0, \text { robust; } 1 \text {, } \\
\text { social } \\
\text { prefrailty; } 2 \text { to } \\
5 \text {, social frailty }\end{array}$} & Disability incidence \\
\hline $\begin{array}{l}\text { Tsutsumimoto et al., } \\
2017^{21)}\end{array}$ & $\begin{array}{l}\text { 4,425 Japanese older adults } \\
\text { (aged } \geq 65 \text { years) }\end{array}$ & $\begin{array}{l}\text { (3) feeling unhelpful to friends or family } \\
\text { (4) livinga lone } \\
\text { (5) not talking to someone every day }\end{array}$ & & $\begin{array}{l}\text { Cognitive and } \\
\text { physical deficits }\end{array}$ \\
\hline $\begin{array}{l}\text { Garre-Olmo et al., } \\
2013^{15)}\end{array}$ & $\begin{array}{l}\text { 1,245 Older adults } \\
\text { (aged } \geq 75 \text { years) }\end{array}$ & $\begin{array}{l}\text { (1) Living alone } \\
\text { (2) Lack of a person to help with ADL } \\
\text { (3) Infrequent contact with family (less } \\
\text { than once a week) } \\
\text { (4) Infrequent contact with friends or } \\
\text { neighbors (less than once a week) } \\
\text { (5) Absence of a confidant } \\
\text { (6) Lack of support for daily living during } \\
\text { the past } 3 \text { months }\end{array}$ & 2 or more & Mortality \\
\hline $\begin{array}{l}\text { Teo et al., } \\
2017^{14)}\end{array}$ & $\begin{array}{l}\text { 2,406 Chinese adults } \\
\text { (aged } \geq 55 \text { years) }\end{array}$ & $\begin{array}{l}\text { Seven-item social frailty index } \\
\text { (1) Living alone } \\
\text { (2) No education } \\
\text { (3) Absence of a confidant } \\
\text { (4) Infrequent contact } \\
\text { (5) Infrequent social activities } \\
\text { (6) Financial difficulty } \\
\text { (7) Socioeconomic deprivation }\end{array}$ & $\begin{array}{l}0 \text {, nil social } \\
\text { frailty; } \\
1 \text {, low social } \\
\text { frailty; } \\
2 \text { to } 7 \text {, high } \\
\text { social frailty }\end{array}$ & $\begin{array}{l}\text { IADL dependency } \\
\text { Severe dependency }\end{array}$ \\
\hline $\begin{array}{l}\text { Bunt et al., } \\
2017^{16)}\end{array}$ & $\begin{array}{l}28 \text { Community-dwelling } \\
\text { elderly people }\end{array}$ & $\begin{array}{l}\text { Social Vulnerability Index Dutch version } \\
\text { (1) Communication to engage in wider } \\
\text { community } \\
\text { (2) Living situation } \\
\text { (3) Social support } \\
\text { (4) Socially oriented activities of daily } \\
\text { living } \\
\text { (5) Leisure activities } \\
\text { (6) Ryff scale } \\
\text { (7) How do you feel about your life } \\
\text { (8) Socioeconomic status }\end{array}$ & $\begin{array}{l}\text { Continuous } \\
\text { variable }\end{array}$ & Validity \\
\hline
\end{tabular}

QoL, quality of life; ADL, activities of daily living; IADL, instrumental ADL. 


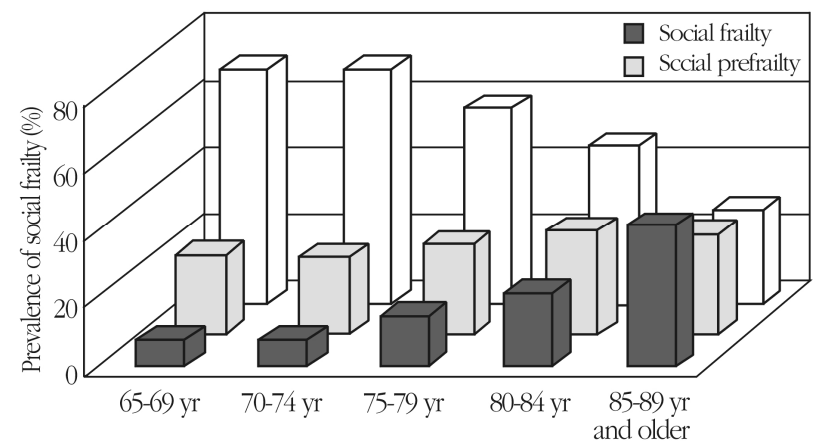

Fig. 1. Prevalence of social frailty in National Center for Geriatrics and Gerontology-Study of Geriatric Syndrome. Adapted from Tsutsumimoto et al. J Am Med Dir Assoc 2017;18:603-7. ${ }^{21)}$

ased with age. Over a fifth (i.e., 22.0\%) of those classified as socially frail were between 80 and 84 years of age, and $41.8 \%$ were 85 years of age and older (Fig. 1). As with physical frailty, the risk of social frailty increases as age increases.

When we consider social frailty, it is still controversial whether physical frailty should be included or not in the definition of social frailty. Since cognitive frailty was first defined as physical frailty and cognitive impairment, ${ }^{22)}$ further discussion is needed in the future.

\section{ADVERSE OUTCOME OF SOCIAL FRAILTY}

A longitudinal evaluation of physical (e.g., presence of chronic disease, balance function, drug use, and nutrition), cognitive/mental (e.g., cognitive function, depression, and quality of life) and social frailty determinants, and the association between incidence of death and type of frailty, was conducted in Spain among 875 older adults aged 74 years and older. Upon follow-up (i.e., average 3.6 years), physical frailty (hazard ratio of 3.09) and social frailty (hazard ratio of 2.69) were found to be factors associated with a significant increase in risk of death. ${ }^{15)}$ Social frailty was assessed using the following 6 items of living alone, presence or absence of caregiver for $A D L$, frequency of contact with family, opportunity to have contact with friends and neighbors, presence or absence of someone to confide in, and necessity for help in daily life in the past 3 months (i.e., help with grocery shopping, preparation of meals, and cleaning). Those older adults who acquired 2 or more items were classified as socially frail. Gaining a better understanding of aspects associated with social frailty among aged individuals allows to consider social frailty as a factor associated with increased risk of death. It has been suggested that physical and cognitive/ mental factors impact the association between social frailty and death. Furthermore, there are concerns around the negative effects of social frailty, as increased levels of social frailty have been found to be associated with a reduction in physical and cogni-

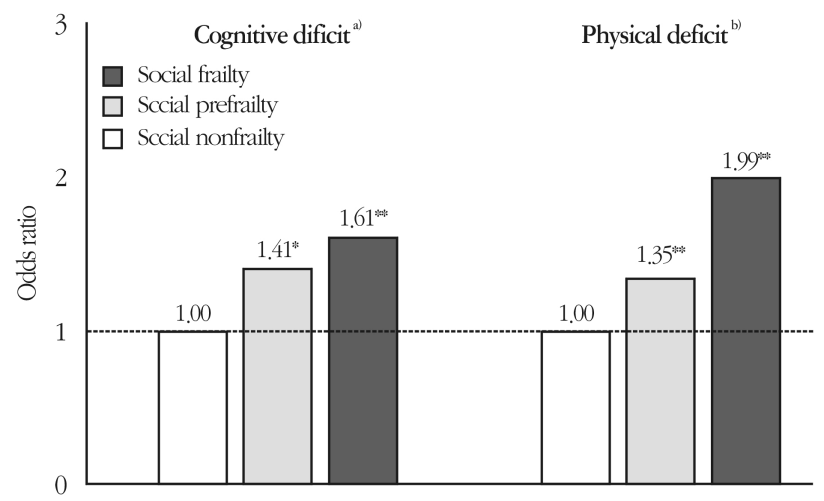

Fig. 2. Associations of social frailty with cognitive and physical deficits. ${ }^{\text {a) }}$ Declines in each domain: memory, attention, executive function, and processing speed. ${ }^{\text {b) }}$ Slowness $(<1.0 \mathrm{~m} / \mathrm{sec})$ or/and weakness (grip strength, $<26 \mathrm{~kg}$ in men, $<18 \mathrm{~kg}$ in women). Covariates: age, sex, education, hypertension, diabetes, hyperlipidemia, medications, working status, physical activity, depressive symptoms. ${ }^{*} \mathrm{p}<0.05$. ${ }^{* *} \mathrm{p}<0.01$. Adapted from Makizako et al. J Am Med Dir Assoc 2015;16:1003.e7-11. ${ }^{4)}$

tive stimulation, accelerating decline in both physical and cognitive functioning.

Classifying social frailty status into 3 groups (i.e., socially nonfrail, socially prefrail, and socially frail), as per the NCGGSGS cohort study, and examining the association between social frailty status and decline in physical and cognitive functions, it was found that the presence of social frailty was significantly associated with a decline in both physical and cognitive functioning among community-dwelling older people (Fig. 2). ${ }^{21)}$ It has been suggested that a decline in physical and cognitive functioning may occur concurrently with the presence of social frailty, as well as in situations characterized by multilevel overlap of frail conditions. Such instances may further accelerate decline in cognitive and physical functioning and may lead to adverse events such as death, hospitalization, incidence of need for care, falling, and decreased ADL. Furthermore, to assess the impact that social frailty has on incidence of need for support/care in the future, we investigated the incidence of need for support/care in 4,304 older adults without recognized need for support/care over a 2-year period. Our results suggested that risk of incidence of need for support/care was significantly higher for older adults with social frailty at baseline (i.e., approximately 1.7 times), compared with those older adults without social frailty (Fig. 3). ${ }^{4}$

Given the above circumstances, both social environment and activity status, and not solely physical frailty, are important factors to consider in the prevention or improvement of frail conditions among community-dwelling older adults. Furthermore, a comprehensive understanding of social frailty, which includes the assessment of economic situation, social network, and social activities, is suggested. 


\author{
Assessment domains \\ (1) going out less frequently \\ (2) rarely visiting friends \\ (3) feeling unhelpful to friends or family \\ (4) living alone \\ (5) not talking with someone every day
}

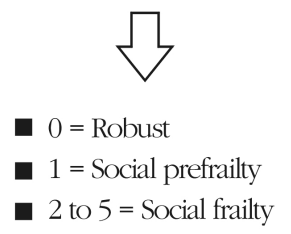

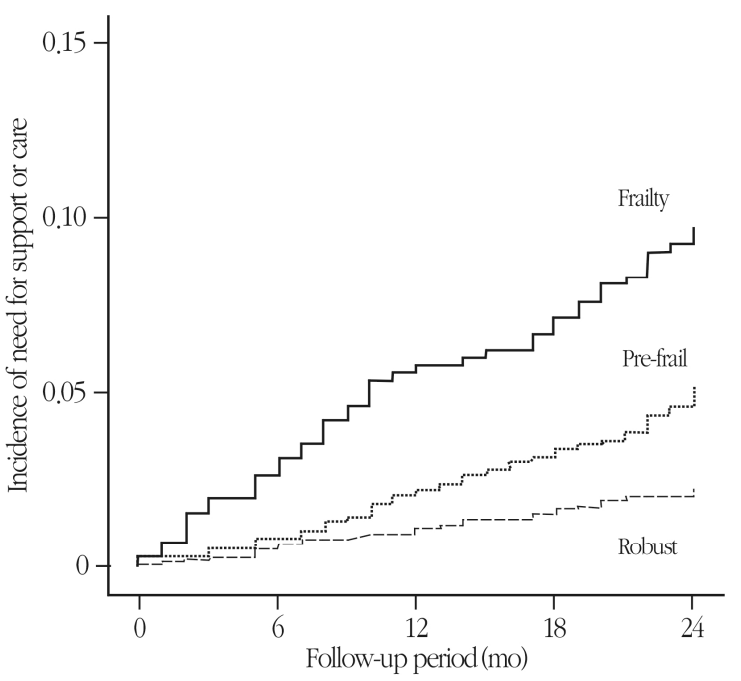

Fig. 3. Social frailty and the risk of incidence of need for support or care. Adapted from Makizako et al. J Am Med Dir Assoc 2015;16:1003.e7-11. ${ }^{4}$

\section{INTERVENTIONS FOR SOCIAL FRAILTY}

Frailty may be considered reversible, and through focused interventions, future risk of incident disability may be prevented. Despite many studies determining the effects of interventions on physical frailty, the number of studies on interventions that target social frailty is limited. ${ }^{23)}$

Studies that have assessed interventions that focus on exercise have found, for example, that supervised group exercises not only promote physical aspects of frailty but also promote interactions with other people, which in turn may lessen or resolve levels of social frailty. ${ }^{24)}$ Previous interventional studies (e.g., resident-centered community intervention programs providing opportunities for social interactions among local older residents) have found that participation in gatherings, such as salon activities that promote social interaction, reduces the risk of incidence of need for care. ${ }^{2)}$ Such intervention programs are widespread throughout various regions in Japan. Participation in such regional gatherings may promote maintenance or improvement of physical, cognitive, and mental functioning.

Moreover, results of regional intervention research conducted in Spain showed that social support interventions, such as visits from nonspecialist volunteers, resulted in nutritional condition and frailty improvement in those elderly who were visited. ${ }^{25}$ In the aforementioned study, visits from volunteers took place twice every week for a 12-week period, with the study primarily focusing on social aspects, including, the promotion of going out, having conversations, and sharing interests and hot topics, all allowing for the opportunity to activate cognitive functions. Such interventions may allow for reductions in frailty in older adults by promoting aspects of health, such as proper nutrition and exercise. ${ }^{25)}$ Inter- ventions focused on social aspects of frailty may result in the reduction of levels of frailty and the prevention of need for care. Importantly, however, further investigation methods that may prove effective are required. In addition, interventions focused on social aspects in older adults with social frailty, including those with physical and cognitive frailty, may prevent the worsening of physical and cognitive frailty as well as prevent the need for care. Furthermore, such interventions may play a role in both the maintenance and improvement of quality of life among older adults, and thus, further investigation is recommended.

\section{CONCLUSION}

Although the importance of addressing both social and physical aspects of frailty in older adults is recognized, we have not reached an agreement on either the most effective methods of assessing frailty or the most effective interventional approaches to address social frailty. It remains important to gather evidence on effective methods of assessing social frailty and effective interventions aimed at reducing frailty. This will allow for the construction and expansion of a system aimed at supporting the promotion of social activity among community-dwelling older adults.

Conflicts of Interest Disclosures: The researchers claim no conflicts of interest.

\section{REFERENCES}

1. Arai H. Implication of frailty in elderly care. Nihon Ronen Igakkai Zasshi 2014;51:497-501.

2. Hikichi H, Kondo N, Kondo K, Aida J, Takeda T, Kawachi 
I. Effect of a community intervention programme promoting social interactions on functional disability prevention for older adults: propensity score matching and instrumental variable analyses, JAGES Taketoyo study. J Epidemiol Community Health 2015;69:905-10.

3. Fratiglioni L, Wang HX, Ericsson K, Maytan M, Winblad B. Influence of social network on occurrence of dementia: a community-based longitudinal study. Lancet 2000;355:1315-9.

4. Makizako H, Shimada H, Tsutsumimoto K, Lee S, Doi T, Nakakubo S, et al. Social frailty in community-dwelling older adults as a risk factor for disability. J Am Med Dir Assoc 2015; 16:1003.e7-11.

5. Lund R, Nilsson CJ, Avlund K. Can the higher risk of disability onset among older people who live alone be alleviated by strong social relations? A longitudinal study of non-disabled men and women. Age Ageing 2010;39:319-26.

6. Fujiwara Y, Shinkai S, Kumagai S, Amano H, Yoshida Y, Yoshida $\mathrm{H}$, et al. Longitudinal changes in higher-level functional capacity of an older population living in a Japanese urban community. Arch Gerontol Geriatr 2003;36:141-53.

7. Woo J, Chan R, Leung J, Wong M. Relative contributions of geographic, socioeconomic, and lifestyle factors to quality of life, frailty, and mortality in elderly. PLoS One 2010;5:e8775.

8. Szanton SL, Seplaki CL, Thorpe RJ Jr, Allen JK, Fried LP. Socioeconomic status is associated with frailty: the Women's Health and Aging Studies. J Epidemiol Community Health 2010; 64:63-7.

9. Gobbens RJ, van Assen MA, Luijkx KG, Wijnen-Sponselee MT, Schols JM. Determinants of frailty. J Am Med Dir Assoc 2010; 11:356-64.

10. Cramm JM, Nieboer AP. Relationships between frailty, neighborhood security, social cohesion and sense of belonging among community-dwelling older people. Geriatr Gerontol Int 2013; 13:759-63.

11. Gobbens RJ, van Assen MA. The prediction of quality of life by physical, psychological and social components of frailty in community-dwelling older people. Qual Life Res 2014;23:2289300 .

12. Gobbens RJJ, van Assen MA. Associations between multidimensional frailty and quality of life among Dutch older people. Arch Gerontol Geriatr 2017;73:69-76.

13. Takabayashi K, Ikuta A, Okazaki Y, Ogami M, Iwatsu K, Matsumura K, et al. Clinical characteristics and social frailty of superelderly patients with heart failure - The Kitakawachi Clinical Background and Outcome of Heart Failure Registry. Circ J 2016;81:69-76.

14. Teo N, Gao Q, Nyunt MSZ, Wee SL, Ng TP. Social frailty and functional disability: findings from the singapore longitudinal ageing studies. J Am Med Dir Assoc 2017;18:637.e13-637.e19.

15. Garre-Olmo J, Calvó-Perxas L, López-Pousa S, de Gracia Blanco M, Vilalta-Franch J. Prevalence of frailty phenotypes and risk of mortality in a community-dwelling elderly cohort. Age Ageing 2013;42:46-51.

16. Bunt S, Steverink N, Andrew MK, Schans CPV, Hobbelen H. Cross-cultural adaptation of the social vulnerability index for use in the Dutch context. Int J Environ Res Public Health 2017;14(11). pii: E1387. https://doi.org/10.3390/ijerph14111387.

17. Andrew MK, Mitnitski AB, Rockwood K. Social vulnerability, frailty and mortality in elderly people. PLoS One 2008;3:e2232.

18. Wallace LM, Theou O, Pena F, Rockwood K, Andrew MK. Social vulnerability as a predictor of mortality and disability: cross-country differences in the survey of health, aging, and retirement in Europe (SHARE). Aging Clin Exp Res 2015;27: 365-72.

19. Andrew MK, Rockwood K. Social vulnerability predicts cognitive decline in a prospective cohort of older Canadians. Alzheimers Dement 2010;6:319-25.e1.

20. Satake S, Shimokata H, Senda K, Kondo I, Toba K. Validity of total Kihon checklist score for predicting the incidence of 3-year dependency and mortality in a community-dwelling older population. J Am Med Dir Assoc 2017;18:552.e1-552.e6.

21. Tsutsumimoto K, Doi T, Makizako H, Hotta R, Nakakubo S, Makino K, et al. Association of social frailty with both cognitive and physical deficits among older people. J Am Med Dir Assoc 2017;18:603-7.

22. Kelaiditi E, Cesari M, Canevelli M, van Kan GA, Ousset PJ, Gillette-Guyonnet $S$, et al. Cognitive frailty: rational and definition from an (I.A.N.A./I.A.G.G.) international consensus group. J Nutr Health Aging 2013;17:726-34.

23. Dedeyne L, Deschodt M, Verschueren S, Tournoy J, Gielen E. Effects of multi-domain interventions in (pre)frail elderly on frailty, functional, and cognitive status: a systematic review. Clin Interv Aging 2017;12:873-96.

24. Tarazona-Santabalbina FJ, Gómez-Cabrera MC, Pérez-Ros P, Martínez-Arnau FM, Cabo H, Tsaparas K, et al. A Multicomponent exercise intervention that reverses frailty and improves cognition, emotion, and social networking in the communitydwelling frail elderly: a randomized clinical trial. J Am Med Dir Assoc 2016;17:426-33.

25. Luger E, Dorner TE, Haider S, Kapan A, Lackinger C, Schindler K. Effects of a home-based and volunteer-administered physical training, nutritional, and social support program on malnutrition and frailty in older persons: a randomized controlled trial. J Am Med Dir Assoc 2016;17:671.e9-671.e16. 